\title{
Increased MET and HGF gene copy numbers are associated with trastuzumab failure in HER2-positive metastatic breast cancer
}

\section{G Minuti', F Cappuzzo*, , R Duchnowska ${ }^{2,12}$, J Jassem ${ }^{3,12}$, A Fabi ${ }^{4}$, T O'Brien $^{5}$, AD Mendoza ${ }^{5}$, L Landi', W Biernat ${ }^{3,12}$, B Czartoryska-Arłukowicz, ${ }^{6,12}$, T Jankowski ${ }^{7,12}$, D Zuziak ${ }^{8,12}$, J Zok, ${ }^{9,12}$, B Szostakiewicz ${ }^{3,12}$, M Foszczyńska-Kłoda ${ }^{10,12}$, A Tempińska-Szałach ${ }^{11,12}$, E Rossi' ${ }^{1}$ and M Varella-Garcia ${ }^{5}$}

'Department of Medical Oncology, Civil Hospital of Livorno, Istituto Toscano Tumori, Viale Alfieri 36, Livorno 57100, Italy; ${ }^{2}$ Department of Oncology, Military Institute of Medicine, 128 Szaserów Street, Warsaw 00-909, Poland; ${ }^{3}$ Department of Oncology and Radiotherapy, Medical University of Gdańsk, 3a M Skłodowskiej-Curie Street, Gdańsk 80-2 I 0, Poland; ${ }^{4}$ Department of Medical Oncology, National Cancer Institute Regina Elena, Via E Chianesi 53 , RM 00 1 44, Rome, Italy; ${ }^{5}$ Molecular Pathology Shared Resource, University of Colorado Cancer Center, I 3001 El 7th Place, CO 80045, Aurora, Colorado, USA; ${ }^{6}$ Department of Oncology, Białystock Oncology Center, 47 Fabryczna Street, Bialystok 15-047, Poland; ${ }^{7}$ Department of Oncology, Lublin Oncology Center, 7 Jaczewskiego Street, Lublin PL- 20090, Poland; ${ }^{8}$ Department of Oncology, Beskidy Oncology Center, 18 Liberation Street, Bielsko-Biała 43-300, Poland; 'Department of Oncology, Warmia and Masuria Oncology Center, 5 Oczapowskiego Street, Olsztyn 10-967, Poland; ${ }^{10}$ Department of Oncology, West Pomeranian Oncology Center, 55 Adama Mickiewicza Street, Szczecin 70-385, Poland; "Department of Oncology, District Hospital of Elblag, 35 Komeńskiego Street, Elblag 82-300, Poland

BACKGROUND: To investigate whether copy number gain of MET or hepatocyte growth factor (HGF) affect trastuzumab sensitivity in HER2-positive metastatic breast cancer (MBC).

METHODS: We analysed 130 HER2-positive MBC treated with trastuzumab-based therapy. MET and HGF gene copy numbers (GCN) were assessed by fluorescence in situ hybridisation (FISH) in primary breast cancer samples. Receiver operating characteristic analysis was applied to find the best cutoff point for both MET and HGF GCN.

RESULTS: MET FISH-positive cases ( $N=36$, mean $\geqslant 3.72$ ) had a significantly higher trastuzumab failure rate (44.4\% vs $16.0 \%$; $P=0.00 \mathrm{I})$ and a significantly shorter time to progression (5.7 vs 9.9 months; HR I.74; $P=0.006$ ) than MET FISH-negative cases $(N=94$, mean <3.72). Hepatocyte growth factor GCN was evaluated in 84 cases $(64.6 \%)$. Receiver operating characteristic analysis identified 33 HGF FISH-positive patients (mean HGF GCN $\geqslant 3.01$ ). HGF FISH-positive status was significantly associated with higher risk of failure (30.3\% vs 7.8\%; $P=0.007$ ) as compared with HGF FISH-negative cases $(\mathrm{N}=5 \mathrm{I}$, mean $<3.0 \mathrm{I})$. MET and HGF FISH-positive status was highly correlated $(P<0.00 \mathrm{I})$ and combination of both biomarkers did not increase predictive value of either considered separately.

CONCLUSION: High GCNs of MET and HGF associate with an increased risk of trastuzumab-based therapy failure in HER2-positive MBC.

British Journal of Cancer (2012) 1 07, 793-799. doi:I0.1038/bjc.2012.335 www.bjcancer.com

Published online 31 July 2012

(c) 2012 Cancer Research UK

Keywords: breast cancer; HER2-positive; HGF; MET

The human epidermal growth factor receptor 2 (HER2) is a transmembrane tyrosine kinase receptor that belongs to the epidermal growth factor receptor (EGFR) family. Approximately $20-25 \%$ of breast cancers are characterised by HER2 protein overexpression or gene amplification, and such events are associated with poor prognosis (Slamon et al, 1987).

The humanised recombinant monoclonal antibody trastuzumab (Herceptin, Genentech, Inc., San Francisco, CA, USA) was the first HER2-targeting agent approved for clinical use in breast cancer (Carter et al, 1992). In HER2-overexpressing or -amplified (HER2positive) breast cancer patients, large phase III trials demonstrated that trastuzumab in combination with chemotherapy was signi-

\footnotetext{
*Correspondence: Dr F Cappuzzo; E-mail: f.cappuzzo@googlemail.com ${ }^{12}$ For the Central and East European Oncology Group (CEEOG). Received 29 March 2012; revised 28 June 2012; accepted 6 July 20I2; published online 31 July 2012
}

ficantly more effective than chemotherapy alone both in advanced disease and in adjuvant setting (Slamon et al, 2001; PiccartGebhart et al, 2005; Romond et al, 2005; Robert et al, 2006; Slamon et al, 2011). Although trastuzumab-based treatments represent today the standard approach for HER2-positive breast cancer, not all patients benefit from this therapy. In metastatic breast cancer (MBC) patients with high degree of HER2 expression, single-agent trastuzumab resulted in 35\% response rate (Vogel et al, 2002), indicating that there is a considerable proportion of individuals potentially refractory to HER2 inhibition even in presence of the drug target. Moreover, one of the major clinical problems encountered with trastuzumab treatment is that MBC patients who initially respond to trastuzumab, show disease progression within 1 year from treatment initiation. A better knowledge of mechanisms responsible for primary and acquired resistance may improve prediction of trastuzumab sensitivity. Several mechanisms of resistance have been described to date, including co-expression of the truncated p95HER2 receptor (Scaltriti 
et al, 2007), activation of the phosphatidylinositol-3-kinase (PTEN/ PI3K/AKT signalling pathway) (Berns et al, 2007) and heterodimerisation with other growth factor receptors including MET (Shattuck et al, 2008), but their clinical relevance is still debatable.

$M E T$ oncogene, localised on chromosome 7 and encoding the dimeric tyrosine kinase receptor for hepatocyte growth factor (HGF), is involved in cell proliferation, survival and angiogenesis (Bottaro et al, 1991). MET-regulated invasive growth has a relevant role in cancer invasion and metastasis (Boccaccio and Comoglio, 2006). MET gene amplification has been described in many human cancers including lung (Tsao et al, 1998; Cappuzzo et al, 2009), gastric (Hara et al, 1998), oesophageal (Miller et al, 2006) and endometrial cancer (Samuelson et al, 2008), and correlates with aggressive disease and poor patient outcome (Graziano et al, 2011). In lung cancer, $M E T$ amplification is responsible for acquired resistance to anti-EGFR tyrosine kinase inhibitors in up to $20 \%$ of cases (Engelman et al, 2007). In breast cancer, MET and HGF overexpression correlates with short relapse-free and overall survival (OS) (Yamashita et al, 1994; Nagy et al, 1996; Yao et al, 1996; Jin et al, 1997; Edakuni et al, 2001; Kang et al, 2003). In a recent study, Raghav et al (2012) reported that high levels of MET protein expression was associated with poor prognosis in early breast cancer. Lindemann et al (2007) reported MET overexpression in $25 \%$ of HER2-positive breast tumours, supporting the hypothesis that both HER2 and MET receptors could synergise in promoting tumour growth. More recently, Shattuck et al (2008) showed that MET contributes to trastuzumab resistance, and a subset of HER2-positive breast cancer patients may benefit from combined inhibition of both HER2 and MET.

Based on previous data, in the current study we aimed to investigate whether MET and HGF gene copy numbers (GCN) are associated with trastuzumab sensitivity in HER2-positive MBC patients.

\section{PATIENTS AND METHODS}

\section{Patient selection}

This retrospective study was conducted in a consecutive series of 130 HER2-positive MBC patients treated with trastuzumab in combination with chemotherapy or as a single agent in 13 centres in Italy and Poland. The HER2 status was determined locally and was defined as positive in presence of gene amplification detected by fluorescence in situ hybridisation (FISH) or in presence of high degree of expression $(3+)$ by immunohistochemistry according to criteria described elsewhere (Hammond et al, 2011). MET and HGF
GCN were evaluated on primary breast tumour tissue obtained at the time of surgery before any trastuzumab-based therapy. Main inclusion criteria adopted for patient selection included availability of primary breast cancer tumour tissue, possibility to verify the response according to RECIST criteria, and availability of clinical data including survival. The study was approved by the ethics committees of all local hospitals and was conducted in accordance with ethical principles stated in the most recent version of the Declaration of Helsinki or the applicable guidelines on good clinical practice, whichever represented the greater protection of the individuals.

\section{Fluorescence in situ hybridisation analyses}

Unstained $4-5 \mu \mathrm{m}$ sections were subjected to a tri-colour FISH assay, using a probe cocktail including HGF sequences (RP11554M24 labelled in Spectrum Gold), MET sequences (RP 11-95I20 labelled in Spectrum Red) and centromere 7 sequences (CEP7, labelled in Spectrum Green, Abbott Molecular, Denver, CO, USA). The FISH assays were performed according to previously described protocol (Cappuzzo et al, 2009), including pre-treatment with $2 \times \mathrm{SSC}$ at $75^{\circ} \mathrm{C}$ and digestion with Proteinase $\mathrm{K}$ for 5-20 min each, co-denaturation at $85^{\circ} \mathrm{C}$ for $15 \mathrm{~min}$, hybridisation for approximately $36 \mathrm{~h}$ and rapid post-hybridisation washes with $2 \times$ SCC/0.4 NP40. Signals were enumerated in at least 50 tumour nuclei per specimen, using epifluorescence microscope with single interference filters at the following excitation/emission wavelengths: $350 / 460$ for blue, $492 / 530$ for green, 530/580 for gold and $572 / 625$ for red, as well as dual (red/green) and triple (blue, red, green) band pass filters. For each slide, the mean and s.d. of copy number per cell of each tested DNA sequence, the percentage of cells with $\leqslant 2,3$ and $\geqslant 4$ copies of each target and the ratio of MET/CEP7 and HGF/CEP7 were calculated. For documentation, images were captured using a CCD camera and merged using dedicated software (Leica Microsystems, Denver, CO, USA) (Figure 1).

MET FISH analysis was successfully performed in all 130 cases. Fluorescence in situ hybridisation analysis of HGF was only performed in 84 cases $(64.6 \%)$, as adequate material was not available in 46 cases.

Lack of additional tumour sections did not allow us to perform additional biomarker analyses.

\section{Statistical analyses}

The primary end point of the study was to assess whether increased MET and HGF GCNs affect sensitivity to trastuzumab in
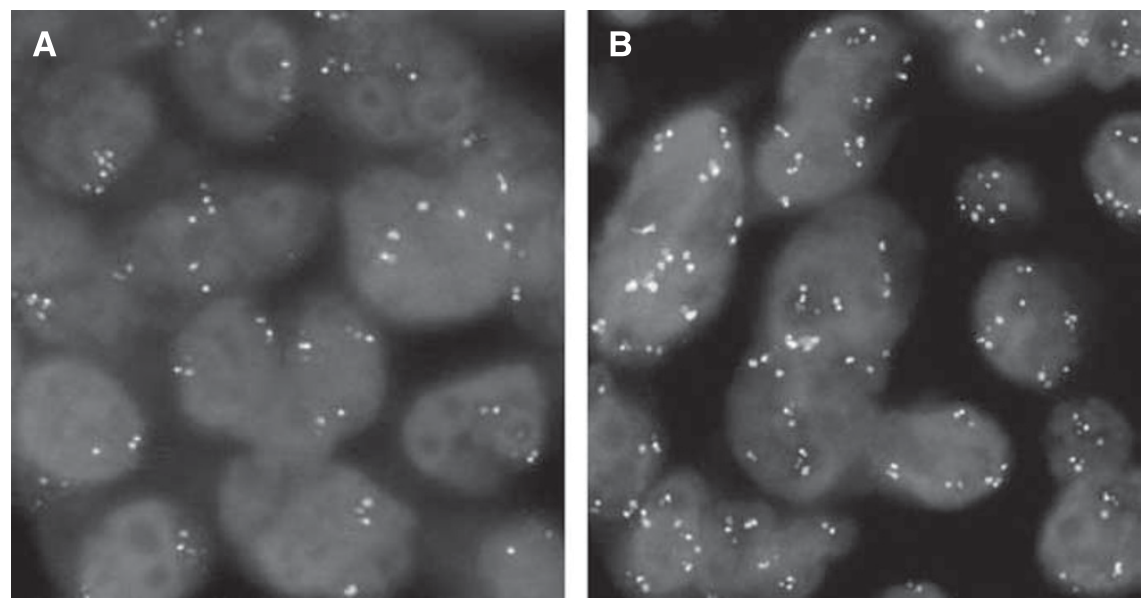

Figure I Hybridisation with the probe mix MET (Spectrum Red) CEP7 (Spectrum Green) and HGF (Spectrum Gold) showing both MET and HGF low GCN in $(\mathbf{A})$ and high GCN in (B). The color reproduction of this figure is available at the British Journal of Cancer online. 
terms of failure rate. Patients were dichotomised into sensitive (complete or partial response and disease stabilisation) and refractory (evidence of progressive disease at the first imaging assessment). The cutoff for MET and HGF GCN discriminating between a positive or negative result was determined using a receiver operating characteristic analysis. Time to progression (TTP) was calculated from the date of first administration of trastuzumab to the date of progression or last assessment. Overall survival was calculated from the date of first administration of trastuzumab to the date of death or last contact. Differences in failure rate were compared by Fisher's exact test or $\chi^{2}$ test. Time to progression, OS and the $95 \%$ confidence intervals for the groups with negative and positive biomarker were evaluated by survival analysis using Kaplan-Meier method (Kaplan and Meier, 1985), and compared using the log-rank test. Statistical significance was set at $<0.05$ for each analysis. Multivariable analysis was performed using logistic regression analysis with a step-down procedure method, with response considered as independent variable. The model was built only on clinical variable, which were significantly associated with response rate at bivariate analysis.

\section{RESULTS}

\section{Patient characteristics}

A total of 130 HER2-positive MBC patients were included in this analysis. The vast majority of patients $(N=109,83.8 \%)$ received trastuzumab in combination with chemotherapy in first-line setting $(N=82,63 \%)$, most frequently in association with taxanes (paclitaxel $32.3 \%$, docetaxel $20.8 \%$ ). The remaining 21 patients $(16.1 \%)$ received single-agent trastuzumab (Table 1). In the entire study population, response rate, including complete and partial response was $49.2 \%$, median TTP was 9.4 months (range: 8.3-10.5 months) and median OS was 28.3 months (range: $22.6-33.9$ months).

\section{MET FISH results}

No MET gene amplification (defined as ratio mean $M E T /$ mean CEP $7>2$ ) was detected and median mean MET GCN was 2.96 (range, 1.66-8.40 copies per cell). In two cases, an equivocal range (MET/ CEP 7 ratio between 1.8 and 2) was observed (MET/CEP 7 ratio of 1.84 and 1.82 , respectively). As illustrated in Figure $2 \mathrm{~A}$, receiver operating characteristic analysis identified a mean of $3.72 \mathrm{MET}$ GCN as the optimal cutoff value for discriminating between sensitive and refractory patients. A total of 36 cases $(27.7 \%)$ had mean $M E T \geqslant 3.72$ (MET FISH positive) and 94 cases $(72.3 \%)$ had mean $M E T<3.72$ (MET FISH negative). As shown in Table 2, MET FISH status was not associated with any clinical or biological characteristic. However, MET FISH-positive patients had a significantly higher failure rate $(44.4 \%$ vs $16.0 \% ; P=0.001)$ and a significantly shorter TTP (median 5.7 vs 9.9 months; HR: 1.74; 95\% CI 1.16-2.62; $P=0.006)$ than $M E T$ FISH-negative patients (Figure 3A). MET FISH-positive patients had slightly shorter OS than MET FISH-negative patients (median 26.4 vs 29.1 months), but the difference was not statistically significant (HR: 1.12; 95\% CI $0.65-1.93 ; P=0.681$; Figure 3B). Importantly, a difference between $M E T$ FISH positive and MET FISH negative was observed in the small subgroup $(N=21)$ of individuals treated with trasuzumab alone. In such subgroup, failure rate $(20.0 \%$ vs $50.0 \%)$ and TTP (median 9.5 vs 1.9 months) were in favour of MET FISH-negative patients, even if, probably because of the small numbers, differences were not statistically significant $(P=0.3$ and $P=0.2$, respectively).

\section{Fluorescence in situ hybridisation results of $H G F$}

Median mean HGF GCN was 2.80 (range, 1.14-6.90 copies per cell). As illustrated in Figure 2B, receiver operating characteristic
Table I Patient characteristics

\begin{tabular}{|c|c|c|}
\hline Characteristics & Total & $\%$ \\
\hline Total no. of patients & 130 & 100 \\
\hline Median age, years (range) & $55(33-80)$ & \\
\hline \multicolumn{3}{|l|}{ Menopausal status } \\
\hline Available/not available & $104 / 26$ & $80 / 20$ \\
\hline Premenopausal/postmenopausal & $18 / 86$ & |7.3/82.7 \\
\hline \multicolumn{3}{|l|}{ Histology } \\
\hline Invasive ductal carcinoma & 114 & 87.7 \\
\hline Invasive lobular carcinoma & 8 & 6.1 \\
\hline Other types & 8 & 6.1 \\
\hline \multicolumn{3}{|l|}{ Grade } \\
\hline 2 & 47 & 36.1 \\
\hline 3 & 68 & 52.3 \\
\hline Not defined & 15 & 11.5 \\
\hline \multicolumn{3}{|l|}{ Hormonal status $(\mathbb{H C})$} \\
\hline ER value $\geqslant 10 \%$ & 52 & 40 \\
\hline PgR value $\geqslant 10 \%$ & 43 & 33 \\
\hline \multicolumn{3}{|l|}{ MiB //Ki67 } \\
\hline Available/not available & $47 / 83$ & $36.1 / 63.8$ \\
\hline Value $\geqslant 10 \%$ & 44 & 93.6 \\
\hline \multicolumn{3}{|l|}{$H E R 2+(I H C I F I S H)$} \\
\hline $\mathrm{IHC} 3+$ and FISH not done & 76 & 58.5 \\
\hline $\mathrm{IHC} 2+$ and FISH amplified & 6 & 4.6 \\
\hline $\mathrm{IHC} 3+$ and FISH amplified & 48 & 36.9 \\
\hline \multicolumn{3}{|l|}{ Treatment } \\
\hline Trastuzumab monotherapy & 21 & 16.1 \\
\hline Trastuzumab with chemotherapy & 109 & 83.8 \\
\hline \multicolumn{3}{|l|}{ Line of treatment } \\
\hline First line & 82 & 63 \\
\hline Second line & 37 & 28.5 \\
\hline Third or subsequent lines & 11 & 8.5 \\
\hline \multicolumn{3}{|l|}{ Drug combined with trastuzumab } \\
\hline None & 21 & 16.1 \\
\hline Paclitaxel & 42 & 32.3 \\
\hline Docetaxel & 27 & 20.8 \\
\hline Vinorelbine & 25 & 19.2 \\
\hline Other & 15 & 11.5 \\
\hline
\end{tabular}

Abbreviations: $\mathrm{MBC}=$ metastatic breast cancer; $\mathrm{ER}=$ oestrogen receptor; $\mathrm{PgR}=$ progesterone receptor; HER2 + =human epidermal growth factor receptor 2 positive (overexpression and/or amplification); $\mathrm{HC}=$ immunohistochemistry; $\mathrm{FISH}=$ fluorescent in situ hybridisation.

analysis identified a mean of $3.01 \mathrm{HGF}$ GCN as the optimal cutoff value for discriminating between sensitive and refractory patients. This cutoff split 33 cases $(39.3 \%)$ as $H G F$ FISH positive (mean $H G F$ GCN $\geqslant 3.01)$ and 51 cases $(60.7 \%)$ as $H G F$ FISH negative (mean HGF GCN <3.01). As summarised in Table 3, HGF FISH status was not associated with any clinical characteristics, whereas there was a strong association between $H G F$ and $M E T$ FISH status $(P<0.001)$ : all $M E T$ FISH-positive cases resulted $H G F$ FISH positive and all HGF FISH-negative cases were $M E T$ FISH negative. Patients who were HGF FISH positive had a significantly higher failure rate $(30.3 \%$ vs $7.8 \% ; P=0.007)$ and a non-significantly shorter TTP (median 9.9 vs 10.5 months, HR 1.10 95\% CI $0.70-1.74, P=0.665)$ than $H G F$ FISH-negative patients (mean <3.01; Figure 4A). Patients who were HGF FISH positive had a not statistically significant longer OS (median 35.2 vs 26.1 months, HR $0.8395 \%$ CI $0.44-1.56, P=0.567$ ) than HGF FISHnegative patients (Figure 4B). 

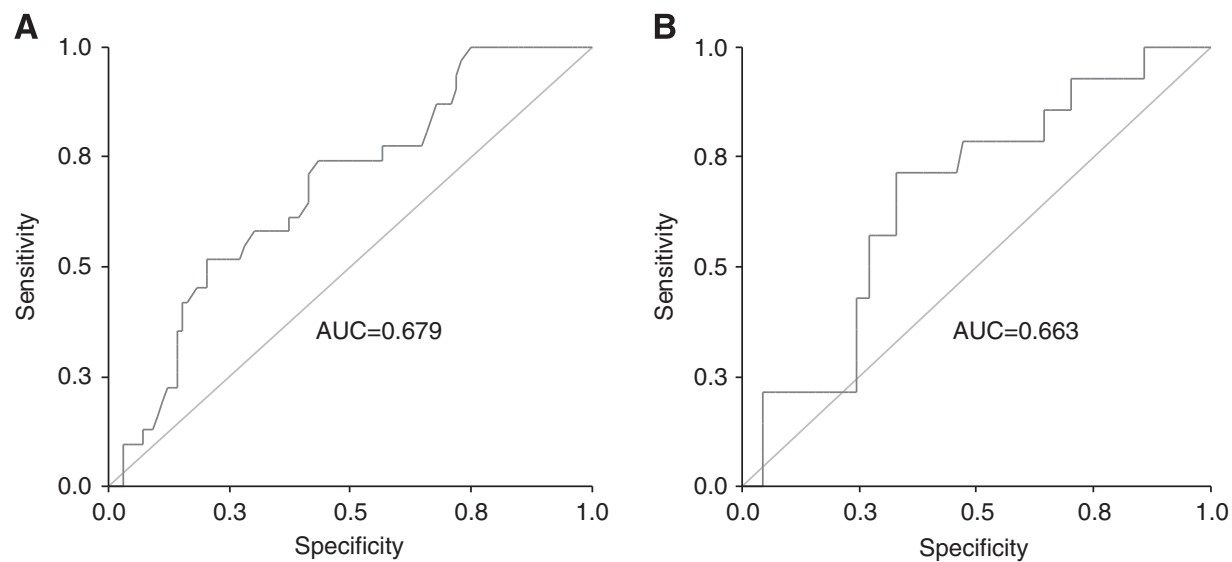

Figure 2 (A) Receiver operating characteristic (ROC) analysis identified a mean of 3.72 MET GCN as the optimal cutoff value discriminating sensitive and resistant population, associated with a sensitivity of $51.6 \%$ and a specificity of $79.8 \%$. AUC (area under the curve) value was 0.679 . (B) ROC analysis identified a mean of 3.0I HGF GCN as optimal cutoff value, associated with a sensitivity of $71.4 \%$ and a specificity of $67.1 \%$. AUC (area under the curve) value was 0.663

Table 2 Association between MET gene copy number and clinical and biological characteristics in HER2-positive metastatic breast cancer patients $(N=130)$

\begin{tabular}{lccc}
\hline Characteristic & $\begin{array}{c}\text { MET FISH } \\
+(\mathbf{N} / \%)\end{array}$ & $\begin{array}{c}\text { MET FISH } \\
-(\mathbf{N} / \%)\end{array}$ & P-value \\
\hline All & $36 / 27.7$ & $94 / 72.3$ & \\
Age $\geqslant 55$ years & $17 / 47.2$ & $47 / 50.0$ & 0.777 \\
Age $<55$ years & $19 / 52.8$ & $47 / 50.0$ & \\
Premenopausal & $6 / 19.4$ & $12 / 16.4$ & 0.719 \\
Postmenopausal & $25 / 80.6$ & $61 / 83.6$ & \\
Invasive ductal carcinoma & $33 / 91.7$ & $81 / 86.2$ & 0.554 \\
Other histology & $3 / 8.3$ & $13 / 13.8$ & \\
Grade 2 & $9 / 29.0$ & $38 / 45.2$ & 0.117 \\
Grade 3 & $22 / 71.0$ & $46 / 54.8$ & \\
IHC ER value $\geqslant 10 \%$ & $15 / 41.7$ & $37 / 39.4$ & 0.810 \\
IHC ER value $<10 \%$ & $21 / 58.3$ & $57 / 60.6$ & \\
IHC PgR value $\geqslant 10 \%$ & $12 / 33.3$ & $31 / 33.0$ & 0.969 \\
IHC PgR value $<10 \%$ & $24 / 66.7$ & $63 / 67.0$ & \\
MiBI/Ki67 value $\geqslant 10 \%$ & $35 / 97.2$ & $92 / 97.9$ & 1.000 \\
MiBI/Ki67 value $<10 \%$ & $1 / 2.8$ & $2 / 2.1$ & \\
\hline
\end{tabular}

Abbreviations: $M E T=$ mesenchymal-epithelial transition factor; HER2 = human epidermal growth factor receptor 2; $E R=$ oestrogen receptor; $\mathrm{PgR}=$ progesterone receptor; $\mathrm{IHC}=$ immunohistochemistry; FISH = fluorescent in situ hybridisation.

\section{MET/HGF FISH combination}

To further investigate the impact of combined MET and HGF GCNs, we analysed the outcome of the 84 patients in whom both biomarkers were assessable. As illustrated in Table 4, overall results confirmed that failure rate was significantly lower in the population negative for both $M E T$ and $H G F(P=0.007)$, with the percentage of progressing patients not significantly different than that detected with a single biomarker assay (failure rate: $7.8 \%$ in MET and HGF negative, $7.8 \%$ in HGF negative only and $16.0 \%$ in $M E T$ negative only).

\section{Univariate and multivariate analysis}

To define which variables were predictive of trastuzumab sensitivity, clinical and biological characteristics, such as age ( $<55$ vs $>55$ years), menopausal status (pre vs post), grade ( 2 vs 3$)$, oestrogen receptor status $(<10 \%$ vs $>10 \%)$, progesterone receptor status $(<10 \%$ vs $>10 \%$ ), proliferative activity (MIB1 $<10 \%$ vs $>10 \%)$, MET GCN $(<3.72$ vs $>3.72)$ and HGF GCN $(<3.01$ vs $>3.01)$ were evaluated in a univariate analysis, using trastuzumab failure rate as end point. Variables found significant in the univariate analysis (MET and $H G F$ GCN) were included in the multivariate model. Because of the strong correlation between $M E T$ and $H G F$, multivariable model did not include both biomarkers at the same time. When MET was excluded, increased GCN of HGF resulted in a odds ratio of 5.87 (95\% CI: 1.21-28.39, $P=0.028)$. When $H G F$ was not included, increased GCN of MET resulted in a odds ratio of 6.02 (95\% CI: 2.24-16.8, $P<0.001)$.

\section{DISCUSSION}

The present study, the first evaluating the role of $M E T$ and HGF GCN in a large cohort of HER2-positive MBC patients treated with trastuzumab-based therapy, provides important evidence for the critical role of HGF/MET signalling pathway for sensitivity to anti-HER2 agents. Increased MET or HGF GCNs were detected in approximately one-fourth cases of HER2-positive breast cancer and were significantly associated with higher risk of treatment failure, supporting a role of anti-MET strategies in breast cancer. Predictive value of MET and HGF GCN was similar and combining both biomarkers did not increase sensitivity of the assay.

MET is a plasma membrane protein that relays signals from the extracellular environment into the cytoplasm, activated when its extracellular domain binds to HGF, also known as scatter factor. Recent data demonstrated that increased MET GCN represents a negative prognostic factor in human malignancies including lung (Cappuzzo et al, 2009) and gastric cancer (Graziano et al, 2011). Preclinical and limited clinical data showed that MET amplification is an event responsible for resistance to agents interfering with the EGFR family. In lung cancer, two studies demonstrated that $M E T$ amplification occurs in approximately $15-20 \%$ of EGFRmutant non-small-cell lung cancers with acquired resistance to the reversible EGFR tyrosine kinase inhibitors, gefitinib or erlotinib (Bean et al, 2007; Engelman and Jänne, 2008). In non-small-cell lung cancer, combination of anti-MET agents with anti-EGFR tyrosine kinase inhibitors (EGFR-TKIs) seems to be one of the most promising strategies to overcome acquired resistance to such agents (Engelman et al, 2007). Although in breast cancer MET is generally not focally amplified (Shattuck et al, 2008), recent studies 

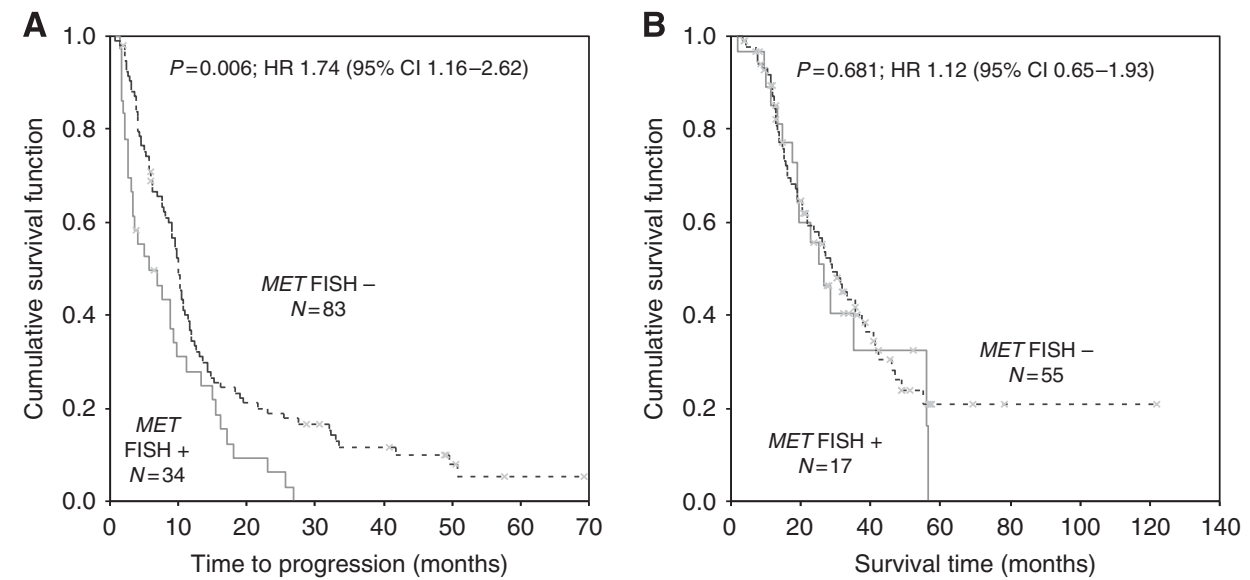

Figure 3 Time to progression $(\mathbf{A})$ and survival $(\mathbf{B})$ in MET FISH-positive and -negative patients, according to the cutoff of 3.72 GCN identified with the receiver operating characteristic (ROC) analysis. MET FISH-positive patients ( $N=36,27.7 \%)$ had a significantly shorter time to progression (median 5.7 vs 9.9 months, HR I.74; $P=0.006$ ) and a non-significant shorter survival (median 26.4 vs 29.I months, HR: I.I2; P=0.68I) than MET FISH-negative $(N=94,72.3 \%)$.

Table 3 Association between HGF gene copy number and clinical and biological characteristics in HER2-positive metastatic breast cancer patients $(N=84)$

\begin{tabular}{lccc}
\hline Characteristic & $\begin{array}{c}\text { HGF FISH } \\
+(\mathbf{N} / \%)\end{array}$ & $\begin{array}{c}\text { HGF FISH } \\
-\mathbf{( N / \% )}\end{array}$ & P-value \\
\hline All & $33 / 39.3$ & $51 / 60.7$ & \\
Age $\geqslant 55$ years & $17 / 51.5$ & $26 / 51.0$ & 0.962 \\
Age $<55$ years & $16 / 48.5$ & $25 / 49.0$ & \\
Premenopausal & 0 & $4 / 11.1$ & 0.287 \\
Postmenopausal & $22 / 100$ & $32 / 88.9$ & \\
Invasive ductal carcinoma & $28 / 84.8$ & $43 / 84.3$ & 0.947 \\
Other histology & $5 / 15.2$ & $8 / 15.7$ & \\
Grade 2 & $9 / 32.1$ & $23 / 51.1$ & 0.112 \\
Grade 3 & $19 / 67.9$ & $22 / 48.9$ & \\
IHC ER value $\geqslant 10 \%$ & $13 / 39.4$ & $19 / 37.3$ & 0.844 \\
IHC ER value $<10 \%$ & $20 / 60.6$ & $32 / 62.7$ & \\
IHC PgR value $\geqslant 10 \%$ & $9 / 27.3$ & $17 / 33.3$ & 0.557 \\
IHC PgR value $<10 \%$ & $24 / 72.7$ & $34 / 66.7$ & \\
MiBI/Ki67 value $\geqslant 10 \%$ & $33 / 100$ & $50 / 98.0$ & 1.000 \\
MiBI/Ki67 value $<10 \%$ & 0 & $1 / 2.0$ & \\
MET FISH + & $21 / 63.6$ & 0 & $<0.001$ \\
MET FISH - & $12 / 36.4$ & $51 / 100$ & \\
\hline Abbreviation: HGF & &
\end{tabular}

Abbreviations: $H G F=$ hepatocyte growth factor; FISH = fluorescent in situ hybridisation; $M E T=$ mesenchymal-epithelial transition factor; HER2 = human epidermal growth factor receptor 2; $E R=$ oestrogen receptor; $\mathrm{PgR}=$ progesterone receptor; $\mathrm{HC}=$ immunohistochemistry.

demonstrated a central role of $M E T$ in trastuzumab resistance. Shattuck et al (2008) showed in a cell line model that attenuation of MET activity leads to sensitisation to trastuzumab, whereas MET activation protects cells from the growth inhibitory effects of trastuzumab by preventing trastuzumab-induced p27 induction. In addition, they showed that MET is co-expressed along with HER2 in HER2-overexpressing breast cancer cells and HER2-positive breast cancer samples. Liu et al (2009) showed that high MET expression is associated with short progression-free survival in HER2-positive MBC patients treated with lapatinib, an irreversible EGFR and HER2 inhibitor. Our findings are in agreement with previous studies confirming that $M E T$ amplification is generally absent in breast cancer and that high MET GCN increases the risk of treatment failure (Shattuck et al, 2008). Response and TTP favoured patients with no MET GCN gain, both in patients treated with trastuzumab plus chemotherapy and in patients treated with trazuzumab alone, supporting the potential therapeutic impact of anti-MET agents in MBC, particularly in combination with anti-HER2 agents.

Recently, Previdi et al (2012) showed that ARQ 197 (tivantinib), a c-MET inhibitor, significantly delays the onset and progression of bone metastases in in vitro and in vivo models, strongly suggesting that targeting c-MET may have therapeutic value in the treatment of MBC. In another study, Liu et al (2011) characterised MET and HER expression and signalling in a panel of human tumour cell lines and demonstrated the differential susceptibility of these cell lines to single agents or combinations of foretinib, a multi-kinase MET inhibitor, with HER-targeted agents, erlotinib or lapatinib. Interestingly, MET-amplified lines with EGFR or HER2 amplification were more sensitive to the combination of foretinib with lapatinib or erlotinib. Overall, these data suggest that therapy including a combination of anti-MET and anti-HER-targeted agents should be tested as a treatment option in HER2-positive patients with $M E T$-amplified or -overexpressing tumours. The idea of combining trastuzumab with other targeted agents is not a new concept in breast cancer, as demonstrated in recent studies comparing trastuzumab with the combination of trastuzumab and pertuzumab, a novel anti-HER2 monoclonal antibody (Baselga et al, 2012; Gianni et al, 2012) or single-agent lapatinib with the association of trastuzumab and lapatinib in trastuzumab-refractory patients (Blackwell et al, 2010).

Another interesting finding in our study was the strong association of MET and HGF GCN. To the best of our knowledge, this is the first study reporting such association in breast cancer. Moreover presence of increased GCN of both MET and HGF in the same tumours explains why a single test was equally predictive than the combination of both assays. Although $M E T$ activation can either occur through ligand-independent or ligand-dependent mechanisms (Kang et al, 2003), our findings suggest that probably ligand-dependent MET activation could represent a relevant mechanism in HER2-positive breast cancer, indicating a potential role for anti-MET monoclonal antibodies in breast cancer. In a recent study, Xie et al (2012) demonstrated that HGF autocrine expression correlated with phospho-MET levels in HGF autocrine cell lines and these cell lines showed high sensitivity to MET inhibition. Our findings together with that of Xie et al (2012) data suggest that MBC patients with high HGF and MET levels could result particularly sensitive to MET therapeutics. 

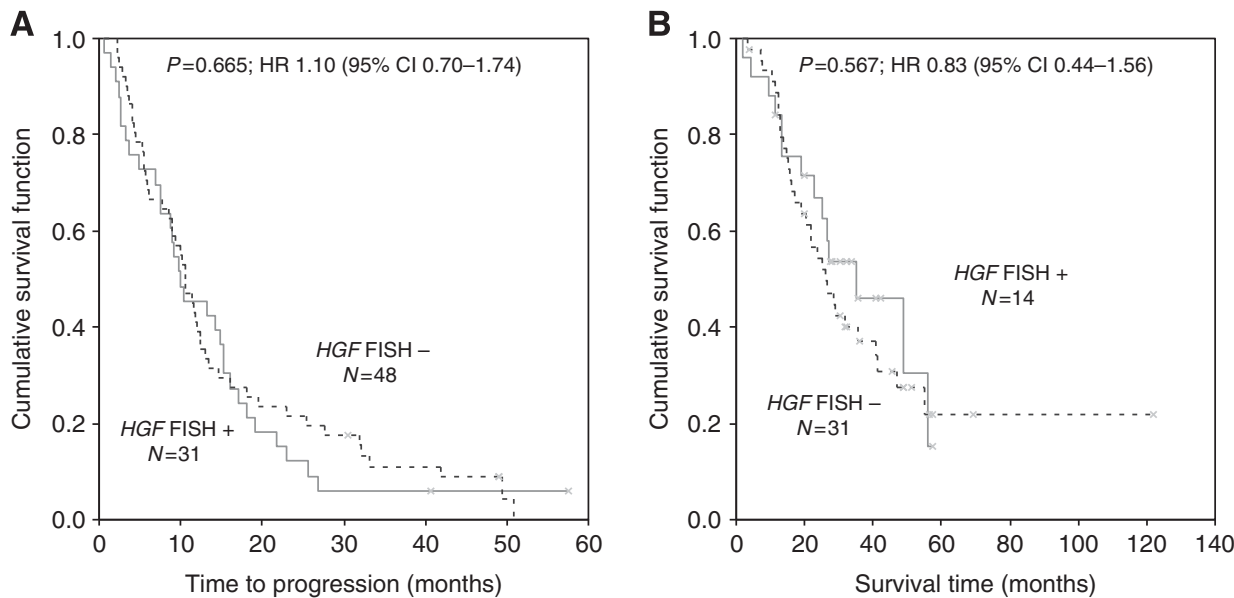

Figure 4 Time to progression $(\mathbf{A})$ and survival $(\mathbf{B})$ in HGF FISH-positive and -negative patients, according to the cutoff of 3.01 GCN identified with the receiver operating characteristic (ROC) analysis. HGF FISH-positive patients ( $N=33,39.3 \%)$ had a not significant shorter time to progression (median 9.9 vs I 0.5 months, HR I.I 0; $P=0.665$ ) and a longer, not statistically significant, survival (median 35.2 vs 26.I months, HR 0.83; $P=0.567$ ) than HGF FISH-negative patients $(N=5 \mathrm{I}, 60.7 \%)$.

Table 4 Outcome according to MET and HGF GCN

\begin{tabular}{|c|c|c|c|c|c|}
\hline & Biomarker & $\mathbf{N}$ & $\begin{array}{c}\text { Failure } \\
\text { rate }(N / \%)\end{array}$ & TTP (months) & OS (months) \\
\hline A & $M E T+/ H G F+$ & 21 & $6 / 28.6$ & 9.2 & 26.4 \\
\hline B & $M E T+/ H G F-$ & 0 & - & - & - \\
\hline C & MET - / HGF+ & 12 & $4 / 33.3$ & 10.3 & 48.8 \\
\hline D & MET - IHGF - & 51 & $4 / 7.8$ & 10.5 & 26.1 \\
\hline \multirow[t]{3}{*}{$P$-value } & A vs $C$ & & 1.0 & 0.2 & 0.4 \\
\hline & A vs D & & 0.054 & 0.2 & 0.9 \\
\hline & $A+C$ vs $D$ & & 0.007 & 0.7 & 0.6 \\
\hline
\end{tabular}

Abbreviations: TTP $=$ time to progression; $\mathrm{OS}=$ overall survival; $M E T=$ mesenchymalepithelial transition factor, $H G F=$ hepatocyte growth factor.

In conclusion, this large retrospective study showed that HGF/MET signalling pathway interferes with trastuzumabbased therapy sensitivity in HER2-positive MBC. These data, together with previous preclinical and clinical studies support further expansion of related studies and clinical development of anti-MET agents in combination with anti-HER2 compounds in HER2-positive MBC.

\section{ACKNOWLEDGEMENTS}

This work was supported by the Italian Association for Cancer Research (AIRC) (IG9425 to FC and LL), Associazione Oncologia Traslazionale (AOT) (to FC) and the National Cancer Institute (P30-CA46934). We are indebted to the pathology department of Milan University for technical support.

\section{Conflict of interest}

The authors declare no conflict of interest.

\section{REFERENCES}

Baselga J, Cortés J, Kim SB, Im SA, Hegg R, Im YH, Roman L, Pedrini JL, Pienkowski T, Knott A, Clark E, Benyunes MC, Ross G, Swain SM, CLEOPATRA Study Group (2012) Pertuzumab plus trastuzumab plus docetaxel for metastatic breast cancer. $N$ Engl J Med 366: $109-119$

Bean J, Brennan C, Shih JY, Riely G, Viale A, Wang L, Chitale D, Motoi N, Szoke J, Broderick S, Balak M, Chang WC, Yu CJ, Gazdar A, Pass H, Rusch V, Gerald W, Huang SF, Yang PC, Miller V, Ladanyi M, Yang CH, Pao W (2007) MET amplification occurs with or without T790M mutations in EGFR mutant lung tumors with acquired resistance to gefitinib or erlotinib. Proc Natl Acad Sci USA 104: 20932-20937

Berns K, Horlings HM, Hennessy BT, Madiredjo M, Hijmans EM, Beelen K, Linn SC, Gonzalez-Angulo AM, Stemke-Hale K, Hauptmann M, Beijersbergen RL, Mills GB, van de Vijver MJ, Bernards R (2007) A functional genetic approach identifies the PI3K pathway as a major determinant of trastuzumab resistance in breast cancer. Cancer Cell 12: $395-402$

Blackwell KL, Burstein HJ, Storniolo AM, Rugo H, Sledge G, Koehler M, Ellis C, Casey M, Vukelja S, Bischoff J, Baselga J, O’Shaughnessy J (2010) Randomized study of lapatinib alone or in combination with trastuzumab in women with erbB2-positive, trastuzumab-refractory metastatic breast cancer. J Clin Oncol 28: 1124-1130

Boccaccio C, Comoglio PM (2006) Invasive growth: a MET-driven genetic programme for cancer and stem cells. Nat Rev Cancer 6: 637-645

Bottaro DP, Rubin JS, Faletto DL, Chan AM, Kmiecik TE, Vande Woude GF, Aaronson SA (1991) Identification of the hepatocyte growth factor receptor as the c-met proto-oncogene product. Science 251: 802-804

Cappuzzo F, Marchetti A, Skokan M, Rossi E, Gajapathy S, Felicioni L, Del Grammastro $M$, Sciarrotta MG, Buttitta $F$, Incarbone $M$, Toschi L, Finocchiaro G, Destro A, Terracciano L, Roncalli M, Alloisio M, Santoro A, Varella-Garcia M (2009) Incresed MET gene copy number negativly affects survival of surgical resected non-small cell lung cancer. J Clin Oncol 27: 1667-1674

Carter P, Presta L, Gorman CM, Ridgway JB, Henner D, Wong WL, Rowland AM, Kotts C, Carver ME, Shepard HM (1992) Humanization of an anti-p185HER2 antibody for human cancer therapy. Proc Natl Acad Sci USA 89: 4285-4289

Edakuni G, Sasatomi E, Satoh T, Tokunaga O, Miyazaki K (2001) Expression of the hepatocyte growth factor/c-Met pathway is increased at the cancer front in breast carcinoma. Pathol Int 51: 172-178

Engelman JA, Jänne PA (2008) Mechanisms of acquired resistance to epidermal growth factor receptor tyrosine kinase inhibitors in non-small cell lung cancer. Clin Cancer Res 14: 2895-2899

Engelman JA, Zejnullahu K, Mitsudomi T, Song Y, Hyland C, Park JO, Lindeman N, Gale CM, Zhao X, Christensen J, Kosaka T, Holmes AJ, Rogers AM, Cappuzzo F, Mok T, Lee C, Johnson BE, Cantley LC, Jänne PA (2007) MET amplification leads to gefitinib resistance in lung cancer by activating ERBB3 signaling. Science 316: 1039-1043 
Gianni L, Pienkowski T, Im YH, Roman L, Tseng LM, Liu MC, Lluch A, Staroslawska E, de la Haba-Rodriguez J, Im SA, Pedrini JL, Poirier B, Morandi P, Semiglazov V, Srimuninnimit V, Bianchi G, Szado T, Ratnayake J, Ross G, Valagussa P (2012) Efficacy and safety of neoadjuvant pertuzumab and trastuzumab in women with locally advanced, inflammatory, or early HER2-positive breast cancer (NeoSphere): a randomised multicentre, open-label, phase 2 trial. Lancet Oncol 13: 25-32

Graziano F, Galluccio N, Lorenzini P, Ruzzo A, Canestrari E, D'Emidio S, Catalano V, Sisti V, Ligorio C, Andreoni F, Rulli E, Di Oto E, Fiorentini G, Zingaretti C, De Nictolis M, Cappuzzo F, Magnani M (2011) Genetic activation of the MET Pathway and prognosis of patients with high-risk, radically resected gastric cancer. J Clin Oncol 29: 4789-4795

Hammond ME, Hayes DF, Wolff AC (2011) Clinical notice for American Society of Clinical Oncology-College of American Pathologists Guideline recommendations on ER/PgR and HER2 testing in breast cancer. J Clin Oncol 29: e458

Hara T, Ooi A, Kobayashi M, Mai M, Yanagihara K, Nakanishi I (1998) Amplification of c-myc, K-sam, and c-met in gastric cancers: detection by fluorescence in situ hybridization. Lab Invest 78: 1143-1153

Jin L, Fuchs A, Schnitt SJ, Yao Y, Joseph A, Lamszus K, Park M, Goldberg ID, Rosen EM (1997) Expression of scatter factor and c-met receptor in benign and malignant breast tissue. Cancer 79: 749-760

Kang JY, Dolled-Filhart M, Ocal IT, Singh B, Lin CY, Dickson RB, Rimm DL, Camp RL (2003) Tissue microarray analysis of hepatocyte growth factor/met pathway components reveals a role for met, matriptase, and hepatocyte growth factor activator inhibitor 1 in the progression of node-negative breast cancer. Cancer Res 63: 1101-1105

Kaplan EL, Meier P (1985) Nonparametric estimation from incomplete observations. J Am Stat Assoc 53: 457-481

Lindemann K, Resau J, Nährig J, Kort E, Leeser B, Annecke K, Welk A, Schäfer J, Vande Woude GF, Lengyel E, Harbeck N (2007) Differential expression of c-Met, its ligand HGF/SF and HER2/neu in DCIS and adjacent normal breast tissue. Histopathology 51: 54-62

Liu L, Shi H, Liu Y, Anderson A, Peterson J, Greger J, Martin AM, Gilmer TM (2011) Synergistic effects of foretinib with HER-targeted agents in MET and HER1- or HER2-coactivated tumor cells. Mol Cancer Ther 10: 518-530

Liu Y, Liu L, Shi H, Greger JG, Jackson KD, Marty-Ethgen P, Gilmer TM, Martin A (2009) cMET expression in HER2 + MBC patients with firstline lapatinib (L) treatment. J Clin Oncol 27: 15s (abstract 1073)

Miller CT, Lin L, Casper AM, Lim J, Thomas DG, Orringer MB, Chang AC, Chambers AF, Giordano TJ, Glover TW, Beer DG (2006) Genomic amplification of MET with boundaries within fragile site FRA7G and upregulation of MET pathways in esophageal adenocarcinoma. Oncogene 25: 409-418

Nagy J, Curry GW, Hillan KJ, McKay IC, Mallon E, Purushotham AD, George WD (1996) Hepatocyte growth factor/scatter factor expression and c-met in primary breast cancer. Surg Oncol 5: 15-21

Piccart-Gebhart MJ, Procter M, Leyland-Jones B, Goldhirsch A, Untch M, Smith I, Gianni L, Baselga J, Bell R, Jackisch C, Cameron D, Dowsett M, Barrios CH, Steger G, Huang CS, Andersson M, Inbar M, Lichinitser M, Láng I, Nitz U, Iwata H, Thomssen C, Lohrisch C, Suter TM, Rüschoff J, Suto T, Greatorex V, Ward C, Straehle C, McFadden E, Dolci MS, Gelber RD, Herceptin Adjuvant (HERA) Trial Study Team (2005) Trastuzumab after adjuvant chemotherapy in HER2-positive breast cancer. $N$ Engl J Med 353: 1659-1672

Previdi S, Abbadessa G, Dalò F, France DS, Broggini M (2012) Breast cancer-derived bone metastasis can be effectively reduced through specific c-MET inhibitor Tivantinib (ARQ 197) and shRNA c-MET knockdown. Mol Cancer Ther 11: 214-223
Raghav KP, Wang W, Liu S, Chavez-Macgregor M, Meng X, Hortobagyi GN, Mills GB, Meric-Bernstam F, Blumenschein GR, Gonzalez-Angulo AM (2012) cMET and phospho-cMET protein levels in breast cancers and survival outcomes. Clin Cancer Res 18(8): 2269-2277

Robert N, Leyland-Jones B, Asmar L, Belt R, Ilegbodu D, Loesch D, Raju R, Valentine E, Sayre R, Cobleigh M, Albain K, McCullough C, Fuchs L, Slamon D (2006) Randomized phase III study of trastuzumab, paclitaxel, and carboplatin compared with trastuzumab and paclitaxel in women with HER-2-overexpressing metastatic breast cancer. J Clin Oncol 24: 2786-2792

Romond EH, Perez EA, Bryant J, Suman VJ, Geyer Jr CE, Davidson NE, Tan-Chiu E, Martino S, Paik S, Kaufman PA, Swain SM, Pisansky TM, Fehrenbacher L, Kutteh LA, Vogel VG, Visscher DW, Yothers G, Jenkins RB, Brown AM, Dakhil SR, Mamounas EP, Lingle WL, Klein PM, Ingle JN, Wolmark N (2005) Trastuzumab plus adjuvant chemotherapy for operable HER2-positive breast cancer. $N$ Engl J Med 353: 1673-1684

Samuelson E, Levan K, Adamovic T, Levan G, Horvath G (2008) Recurrent gene amplifications in human type I endometrial adenocarcinoma detected by fluorescence in situ hybridization. Cancer Genet Cytogenet 181: $25-30$

Scaltriti M, Rojo F, Ocaña A, Anido J, Guzman M, Cortes J, Di Cosimo S, Matias-Guiu X, Ramon y Cajal S, Arribas J, Baselga J (2007) Expression of p95HER2, a truncated form of the HER2 receptor, and response to anti-HER2 therapies in breast cancer. J Natl Cancer Inst 99: 628-638

Shattuck DL, Miller JK, Carraway 3rd KL, Sweeney C (2008) Met receptor contributes to trastuzumab resistance of Her2-overexpressing breast cancer cells. Cancer Res 68: 1471-1477

Slamon D, Eiermann W, Robert N, Pienkowski T, Martin M, Press M, Mackey J, Glaspy J, Chan A, Pawlicki M, Pinter T, Valero V, Liu MC, Sauter G, von Minckwitz G, Visco F, Bee V, Buyse M, Bendahmane B, Tabah-Fisch I, Lindsay MA, Riva A, Crown J, Breast Cancer International Research Group (2011) Adiuvant trastuzumab in HER-2 positive breast cancer. N Engl J Med 365: 1273-1283

Slamon DJ, Clark GM, Wong SG, Levin WJ, Ullrich A, McGuire WL (1987) Human breast cancer: correlation of relapse and survival with amplification of the HER-2/neu oncogene. Science 235: 177-182

Slamon DJ, Leyland-Jones B, Shak S, Fuchs H, Paton V, Bajamonde A, Fleming T, Eiermann W, Wolter J, Pegram M, Baselga J, Norton L (2001) Use of chemotherapy plus a monoclonal antibody against HER2 for metastatic breast cancer that overexpresses HER2. N Engl J Med 344: 783-792

Tsao MS, Liu N, Chen JR, Pappas J, Ho J, To C, Viallet J, Park M, Zhu H (1998) Differential expression of Met/hepatocyte growth factor receptor in subtypes of non-small cell lung cancer. Lung Cancer 20: 1-16

Vogel CL, Cobleigh MA, Tripathy D, Gutheil JC, Harris LN, Fehrenbacher L, Slamon DJ, Murphy M, Novotny WF, Burchmore M, Shak S, Stewart SJ, Press M (2002) Efficacy and safety of trastuzumab as a single agent in first-line treatment of HER2-overexpressing metastatic breast cancer. J Clin Oncol 20: 719-726

Xie Q, Bradley R, Kang L, Koeman J, Ascierto ML, Worschech A, De Giorgi V, Wang E, Kefene L, Su Y, Essenburg C, Kaufman DW, DeKoning T, Enter MA, O'Rourke TJ, Marincola FM, Vande Woude GF (2012) Hepatocyte growth factor (HGF) autocrine activation predicts sensitivity to MET inhibition in glioblastoma. Proc Natl Acad Sci USA 109: 570-575

Yamashita J, Ogawa M, Yamashita S, Nomura K, Kuramoto M, Saishoji T, Shin S (1994) Immunoreactive hepatocyte growth factor is a strong and independent predictor of recurrence and survival in human breast cancer. Cancer Res 54: 1630-1633

Yao Y, Jin L, Fuchs A, Joseph A, Hastings HM, Goldberg ID, Rosen EM (1996) Scatter factor protein levels in human breast cancers: clinicopathological and biological correlations. Am J Pathol 149: 1707-1717

This work is published under the standard license to publish agreement. After 12 months the work will become freely available and the license terms will switch to a Creative Commons Attribution-NonCommercial-Share Alike 3.0 Unported License. 